\title{
Golden ratio in congestive heart failure: A promising proportion for prognosis and decompensation. Authors' reply
}

\author{
Anna Kowalczys ${ }^{1,2}$, Michał Bohdan ${ }^{1}$, Marcin Gruchała ${ }^{1}$ \\ ${ }^{1}$ First Department of Cardiology. Medical University of Gdansk, Poland \\ ${ }^{2}$ Department of Pharmacology. Medical University of Gdansk, Poland
}

We would like to thank Yetkin et al. [1] for interesting and insightful comments regarding our publication. They suggested that systolic blood pressure/diastolic blood pressure (SBP/DBP) ratio is associated with golden ratio and might be useful for stratifying the risk of heart failure (HF) decompensation [1].

Heart failure decompensation is one of the most difficult challenges in the management of patients with $\mathrm{HF}$ [2]. It needs to be highlighted that each HF decompensation should be regarded as a life-threatening condition and adversely affects the prognosis in this group of patients [2]. One of the very important research goals in the field of $\mathrm{HF}$ is the search for factors that may lead to a reduction in HF decompensations [2]. Early identification of potential risk factors enables the improvement of effectiveness of care in patients with chronic HF. In this context, the prospect of using new tools to identify patients at high risk of $\mathrm{HF}$ decompensation is very interesting and requires further attention.

The golden proportion was known already in antiquity and was attributed to exceptional aesthetic values [3, 4]. Golden ratio, estimated as phi $=1.618$, has been described not only in mathematics but also in many other fields such as nature, architecture, art and science [3, 4]. Many authors have indicated a possible link of golden ratio with the human cardiovascular system [3-10]. Several data demonstrated the existance of golden proportion particularly in left ventricle dimensions measured in transthoracic echocardiography [3, 5-7]. Moreover, Gibson et al. [9] revealed an association between the Fibonacci sequence and distribution of culpirit lesions in coronary arteries in patients with myocardial infarction with ST-segment elevation. Many researchers have also been interested in the relationship between the golden proportion, $\mathrm{SBP} / \mathrm{DBP}$ and $\mathrm{DBP} /$ pulse pressure ratios $[3,4,8$, 10]. Recently, Papaioannou et al. [8] analyzed the NHANES data from 31,622 individuals and reported that participants with SBP/DBP values that deviate from the 1.618 have a significantly higher risk of death in comparison to those with blood pressure values close to golden ratio.

Yetkin et al. [1] observed that in our study population SBP/DBP ratio is very close to 1.618 in stable patients with HF. Moreover, they estimated that SBP/DBP ratio in patients with recent HF decompensation differs significantly from this value [1]. Indeed, taking into account the above observations, SBP/DBP ratio value may be important in estimating the risk of decompensation in stable patients with HF. However, it should be emphasized that our study had limitations that may have affected the above results. First, the population in our study was small and diverse and included not only patients with HF due to coronary artery disease, but were also caused by other etiological factors. Secondly, most of our patients had various comorbidities and cardiovascular risk factors. Finally, all patients were treated pharmacologically with drugs that affect blood pressure and heart rate, which may have had an impact on the potential prognostic value of the SBP/DBP ratio. Furthermore, the methodology of our study included only daytime multiple blood pressure measurements during hospitalization [11]. Meanwhile, Yetkin et

Address for correspondence: Anna Kowalczys, MD, First Department of Cardiology, Medical University of Gdansk, ul. Dębinki 7, 80-211 Gdańsk, Poland, tel: +48 5834925 00, fax: +48 58346 12 01, e-mail: anna.roz@gumed.edu.pl 
al. [10] suggested that particularly the night-time SBP/DBP ratio measurements were close to the golden ratio. Therefore, future research in this area should take into account the application of 24 -hour ambulatory blood pressure monitoring.

Currently, there is still little data in the literature on the prognostic significance of SBP/DBP ratio, double product and other ratios involving heart rate and blood pressure in patients with HF. Therefore, large studies are needed to determine their usefulness and applicability in clinical practice.

\section{Conflict of interest: None declared}

\section{References}

1. Yetkin E, Ozturk S, Cuglan B, et al. Golden ratio in congestive heart failure: A promising proportion for prognosis and decompensation. Cardiol J. 2020; 27(6), 904-905, doi: 10.5603/ CJ.2020.0177.

2. Ponikowski P, Voors AA, Anker SD, et al. ESC Scientific Document Group. 2016 ESC Guidelines for the diagnosis and treatment of acute and chronic heart failure: The Task Force for the diagnosis and treatment of acute and chronic heart failure of the European Society of Cardiology (ESC) Developed with the special contribution of the Heart Failure Association (HFA) of the ESC. Eur Heart J. 2016; 37(27): 2129-2200, doi: 10.1093/ eurheartj/ehw128, indexed in Pubmed: 27206819.

3. Yalta K, Ozturk S, Yetkin E. Golden Ratio and the heart: A review of divine aesthetics. Int J Cardiol. 2016; 214:
107-112, doi: 10.1016/j.ijcard.2016.03.166, indexed in Pubmed: 27060268.

4. Ozturk S, Yalta K, Yetkin E. Golden ratio: A subtle regulator in our body and cardiovascular system? Int J Cardiol. 2016; 223: 143-145, doi: 10.1016/j.ijcard.2016.08.147, indexed in Pubmed: 27537743.

5. Henein MY, Zhao Y, Nicoll R, et al. Golden Ratio Collaborators. The human heart: application of the golden ratio and angle. Int J Cardiol. 2011; 150(3): 239-242, doi: 10.1016/j.ijcard.2011.05.094, indexed in Pubmed: 21703707.

6. Çelik M, Gökoğlan Y, Develi S, et al. The golden ratio of the human heart. Gulhane Med J. 2015; 57(1): 1-4, doi: 10.5455/ gulhane.43279.

7. Yetkin E, Çelik T, Arpaci M, et al. Left ventricular diameters as a reflection of ,extreme and mean ratio”. Int J Cardiol. 2015; 198: 85-86, doi: 10.1016/j.ijcard.2015.06.164, indexed in Pubmed: 26156320 .

8. Papaioannou TG, Vavuranakis M, Gialafos EJ, et al. Blood pressure deviation from the golden ratio $\varphi$ and all-cause mortality: a pythagorean view of the arterial pulse. Int J Appl Basic Med Res. 2019; 9: 55-57, doi: 10.4103/ijabmr.IJABMR 103_18.

9. Gibson C, Gibson W, Murphy S, et al. Association of the Fibonacci Cascade with the distribution of coronary artery lesions responsible for ST-segment elevation myocardial infarction. Am J Cardiol. 2003; 92(5): 595-597, doi: 10.1016/s0002-9149(03)00731-8.

10. Yetkin E, Topbaş U, Yanik A, et al. Does systolic and diastolic blood pressure follow Golden Ratio? Int J Cardiol. 2014; 176(3): 1457-1459, doi: 10.1016/j.ijcard.2014.08.065, indexed in Pubmed: 25150476.

11. Kowalczys A, Bohdan M, Gruchała M. Prognostic value of daytime heart rate, blood pressure, their products and quotients in chronic heart failure. Cardiol J. 2019; 26(1): 20-28, doi: 10.5603/ CJ.a2017.0130, indexed in Pubmed: 29131282. 
